\title{
Patient Turnover in a new Psychogeriatric Day Hospital: a Pluralistic Evaluation
}

\author{
GILBERT SMITH† and CAROLINE CANTLEY + \\ with VALERIE RITMAN§
}

\section{ABSTRACT}

Studies designed to evaluate the services of a health or welfare institution face the major difficulty of selecting evaluative criteria to serve as measures of successful performance. This paper explores that difficulty in the context of a study of a new psychogeriatric day hospital. The study and its methods of data collection are described. 'Patient turnover' features prominently as a measure of success within the hospital. Consultants, nurses, general practitioners, social workers, staff of a related hospital and patients' relatives interpret this measure in different ways and adopt different strategies to pursue 'success' in their own interests. These differences are described. The paper concludes that a 'pluralistic evaluation' has several advantages as compared to other approaches.

\section{Introduction}

This paper explores one of the abiding difficulties of research designed to evaluate the performance of a health or welfare institution. Stated in its simplest form the difficulty is this. Evaluative research rests upon a clear measure of the 'success' of an organisation's performance. Yet in practice the various members of an organisation often confuse

- This article is a substantially revised version of an early working paper on the project originally given at the British Sociological Association, Medical Sociology (Scottish Branch) Conference, Pitlochry, March 1982.

$\dagger$ Professor of Social Administration, University of Hull, England.

$\ddagger$ Research Assistant, Department of Community Medicine, University of Aberdeen, Scotland.

$\S$ Research Student, Department of Social Administration and Social Work, University of Glasgow, Scotland. 
satisfactory achievement of their own tasks with achievement of the tasks of the organisation as a whole. Thus different constituent groups of patients, relatives, staff and clients (for example), assign a different meaning of 'success' to the work of the organisation. This occurs even when there is apparently some common overall purpose for the institution's activities. It is then difficult for evaluators to know which criterion to employ and what operational definition of the criterion they should use. ${ }^{1}$

In the paper that follows we shall describe how we tackle this difficulty in a study that we are conducting on the evaluation of a new psychogeriatric day hospital. We shall suggest that it is useful to study the various ways in which group interest is associated with success, as a central part of evaluative research. We identify several constituent groups of hospital personnel and, taking each in turn, describe first how the work of their particular segment of the organisation structures the perception and pursuit of what 'success' entails, and secondly how practices in line with such pursuits create problems for other groups. We also describe the organisational strategies which each group uses to avoid operational problems for itself. Thus we shall try to suggest a way not only of solving the methodological difficulty that we have mentioned, but of actually turning it to advantage. Our basic argument is that evaluation must take account of separate group interests, interpretations and influences. Indeed, only by so doing does it achieve a competent account of the way in which a hospital or any other service organisation achieves 'success'.

So in order to reach some new understanding of the problems of evaluative research we shall now describe our study and the methods of data collection used. Then we shall present some relevant findings. Finally we shall discuss the advantages of our approach (we call it 'pluralistic evaluation') as compared to other approaches.

\section{Study and Methods}

The day hospital that we are studying has 25 places for elderly patients of varying psychiatric diagnoses. It caters for about 35 patients each week. The majority are transported daily to the hospital by bus from the surrounding towns and villages. Patients vary widely in physical and mental condition although all are ambulant. Their problems are described in hospital and social work records as including aggression, wandering, incontinence, inability to cope with the activities of daily living, sleep disturbance, risk with electricity, gas or fires, mood 
disturbance, hallucinations, general forgetfulness and inability to communicate.

During any one year $13^{0-1} 5^{\circ}$ patients are referred of whom around $75 \%$ are admitted. At the end of a year about $60 \%$ of those admitted during the year have been discharged. Usually, each patient attends on two or three occasions a week for varying periods from one week upwards. The span of attendance averages about 4 months. About $15 \%$ of discharged cases are readmitted at some future stage. ${ }^{2}$

The hospital is a purpose-built structure situated in the grounds of Park Hospital, a much older and larger institution which has in-patient, mostly long-stay, wards for geriatric, psychogeriatric and mentally defective patients. There is some interchange of patients and services between the two institutions and the consultant psychiatrist in charge of the day hospital is also responsible for some of the wards in Park Hospital. Much of the responsibility for day-to-day running lies with the nursing sister, who works almost exclusively in the day hospital. She is accountable to senior nursing staff based in Park Hospital. Social work services are provided by a social worker on the staff of the Region's social work department, assigned to work full time in connection with patients of the day hospital and Park Hospital. ${ }^{3}$

The general methods of data collection and the early history of the project have been described by Smith. ${ }^{4}$ The specific materials used in this paper were collected in the following way. We interviewed I 6 members of staff involved in the planning and operation of the day hospital, including the psychiatrist, senior nursing staff, nurses, social worker, secretary, medical officer and Health Board officials. The interviews were semi-structured, tape-recorded and subsequently transcribed. Respondents were asked directly about the success of the hospital and how they measured it, but often statements about assessment criteria emerged most clearly in discussions of particular aspects of the development and operation of the services.

We collected data over a two-year period on the operation of the day hospital through observations of the weekly hospital meetings attended by day hospital staff and nurses in charge of the three psychogeriatric wards in Park Hospital. At these meetings, admissions and discharges to the day hospital are, amongst other matters, discussed. We also observed a fortnightly Relatives Support Group which is run by some members of the day hospital staff and attended by the relatives of some patients. Finally we drew upon a pilot study of the medical records of patients of the day hospital during its first 14 months of operation, up to the end of 1980 , to produce simple quantitative estimates of some features of the hospital's service. 
Thus, throughout the paper we have essentially two different kinds of data which we use for different purposes. We draw upon interview material to describe the way in which separate groups construe their own interests and the way in which they see other interests as impinging upon them. We draw upon observational and record materials to describe the strategies that various groups adopt in order to pursue their own interests as they see them. But given the difficulties of direct observation in many hospital settings, the methodological divisions are not always that neat, and on occasions we also base our accounts of the outcome and impact of various strategies upon interview materials.

\section{Findings}

\section{The Importance of Patient Turnover}

In the course of studying staff and relative perceptions of the way in which the hospital should operate we encountered, particularly, widespread advocacy in general terms of the importance of 'turnover' in the population of the institution. ${ }^{5}$ This concern mirrors the frequent references to 'patient flow' as a criterion for measuring the success of day care for the elderly, which appear in the psychiatric literature ${ }^{6}$ It is generally felt to be rather obvious that any service claiming to be effective should at least be able to discharge patients regularly and admit new cases. So, throughout the day hospital, there is widespread reference to the 'flow' of patients through the system of referral, admission, treatment and discharge, into and out of the hospital and related institutions, as a basis for organisational practice. 'Patient turnover' is a key evaluative measure.

Some extracts from our data fill out this view of the way in which the institution should function. First it is widely suggested that the hospital should reduce demand for in-patient beds. A nurse explained:

Well, the main achievement is to keep the elderly as fit and as able as we can in the community and to try and reduce the demand on in-patient beds and to prevent people coming into beds prematurely and keep the patient in the community as long as we can.

The hospital should also, as a Senior Nurse commented, shorten the waiting list for these beds:

I was led to believe that the whole purpose of the day hospital... was because of the waiting list for places which we did not have for psychogeriatrics.

and as an administrator added, prevent and delay admission to in-patient beds; 
we find that we're getting far too many patients in who should be in the community and hopefully the day hospital is going to stop them coming in at an early stage and the longer we can keep people in the community the better it's going to be for themselves and the Health Service as a whole.

It is also felt, again in the words of a nurse, that the hospital should improve the matching of categories of beds with the correct categories of patients :

Now that...most of the psychogeriatric population who've got a psychiatric problem are coming through [the day hospital], we're getting people into the right places that they should be... I think we're routeing them the right way now. I think they are having an effect on the in-patient population. The right people are getting in, put it that way;

and, as described by a psychiatrist, more effectively mesh the referral of patient to psychogeriatric medical care with other services:

When a referral comes [here] not all these patients are . . admitted... It quite often turns out that [the social worker] is able to arrange some other kind of help, such as somebody going for day care in one of the residential units or even exceptionally going into an eventide home, so that apart from the places we have here, the team is really functioning on a wider basis.

Above all, 'silting up' should be avoided both in the day hospital itself and in other parts of the hospital system to which it relates. As a senior nurse said;

We thought that if [the day hospital] was going to be effective at all and relieve a great many families, then there would have to be a throughput, patients would have to be in and out.

In short, there is widespread accord with the general rubric that the day hospital should, as a nurse said;

...provide us with a stepping stone, both from the community into the hospital and from the hospital into the community.

However, this does not mean that we have in the goal of 'turnover', a simple and self-evident criterion for evaluation. For when we examine in detail how different groups pursue this overall objective, how they perceive the consequences of pursuing it in a variety of ways, and how they adopt particular organisational strategies, we come back to our problem. Much of the hospital's work with patien ts cannot be understood if we presume that advantage for all lies simply in the shared policy of patients entering and leaving the hospital as rapidly as possible. It very much depends upon just which categories of patients are moving where, how, and with what consequences for what groups of staff, relatives and other patients. There may well be agreement that a day 
hospital should serve to move patients from the community into in-patient beds and from such beds into the community. But for each group involved in the system of care of which the hospital is part, this perspective yields advantage only when idiosyncratically interpreted. Therefore, as a part of evaluative research, we have to examine the way in which, within the broad consensus, each group perceives and pursues its own interests in patient turnover.

We shall consider six groups in the following order: consultants, nurses, general practitioners, social workers, staff of a related hospital and patients' relatives.

\section{Consultant psychiatrists}

The first of the constituent groups of such a hospital is the consultants. ${ }^{7}$ Their interest in extending provision for care of psychogeriatric patients throughout the health board provided much of the original impetus for establishing the Day Hospital. (Blake ${ }^{8}$, Pathy ${ }^{9}$, Silverman and $\mathrm{Val}^{10}$, and Baker and Byrne ${ }^{11}$, have all reported that the role which day hospitals can play in alleviating the demand for in-patient facilities is one of their major contributions.)

The consultants were hopeful that measures would be taken which would have some continuing long-term effect on improving patient flow. Essentially this means, for consultants, that the day hospital should provide them with an additional avenue when considering how to dispose of referrals from GPs. That is the immediate task in hand, described by one consultant thus:

...say as part of my normal duties, maybe my week on call, if I am asked to see an 80-year-old lady within the [day hospital] area, now before, that was a nightmare because you knew very well that the possibility of getting a bed in [the psychiatric hospital] was remote as it still is and so there was not really very much you could offer... First of all I would ask [the social worker] to go and visit and then this may lead to day hospital and to quite a range of things and believe me that's a great relief...I know it's made a tremendous difference... It's relieved pressure on psychiatrists I think! (Laughs). I don't know whether it has made any impact on the waiting list or not - because waiting lists are probably tending to increase anyway.

However, more is entailed in successful patient flow for consultants than the hospital simply being an additional referral point. Whereas GPs are primarily interested in the hospital admitting cases, consultants seek also to discharge patients. Goldstein et al. ${ }^{12}$, Irvine ${ }^{13}$ and Pathy ${ }^{14}$, amongst others, have reported a tendency for such day hospitals to 'silt up' because of the difficulties encountered in discharging patients. 
If the day hospital is to make any contribution to solving the problem of the consultants it must maintain its capacity for channelling patients to as well as from other parts of the system. Thus preventing any blockage of patient flow through the day hospital has necessarily become one of the primary concerns of the psychiatrist in charge, a concern which is reflected in the frequent review of occupancy rates at the hospital meetings.

There are several ways in which consultants can attempt to prevent a blockage in the aspects of the system which are of particular concern to them. First, an attempt may be made to control bombardment; second, patients may be discharged whenever possible; third, patients may be referred to other services; fourth, there are a variety of arrangements for the use of the hospital in conjunction with in-patient beds. In the context of our present discussion the most interesting feature of them all is the way in which each creates problems for some other group within the system.

\section{(I) CONTROLLING BOMBARDMENT}

The first way of trying to ensure that the day hospital avoids silt-up is for the consultant psychiatrist to attempt control over the bombardment of referrals from outside sources. A major cost of this strategy is that it conflicts with the interests of GPs and endangers the smooth relations between the hospital and general practice. Since GPs are the major referral agents, this is important. While the day hospital can simply refuse further admissions on the grounds of no available places or whatever, constant refusal is obviously unwelcome by referrers. A more effective approach for the hospital, described here by an administrator, is the control of demand by limiting the promotion of referrals:

it was earlier this year when we were trying to review the type of patients that GPs were offering for treatment but we rather sidestepped that one because... [the psychiatrist] wanted to wait; the last thing we wanted to do was to get a flood of referrals that we couldn't respond to.

Controlling demand by limiting the promotion of referrals is a feature, too, of the day hospital's relations with other consultant psychiatrists in the area psychiatric hospital. They are not actively encouraged to consider the day hospital for use with their in-patients on being discharged home.

In practice this caution is effective. Concern to avoid 'opening the floodgates' for referrals from other psychiatrists results in only $7.8 \%$ of day hospital admissions coming from that source. 
(2) AGTIVE DISCHARGE

A second way of preventing any blockage is to discharge patients whenever possible. Given the widely recognised problems which characterise diagnosis and prognosis in the field of psychogeriatric medicine it is clear that the discharge decision is a topic for considerable discretion. ${ }^{15}$ Patients whose condition has deteriorated as well as those whose condition has improved may be discharged. ${ }^{16}$ Goldstein et al., ${ }^{17}$ in a study of a psychogeriatric day hospital, noted that despite a $42 \%$ discharge rate, 'After one year of operation we have not had a single discharge as a result of patient improvement'. Studies by Blake ${ }^{18}$ and McDonald et al. ${ }^{19}$ also show low rates of discharge due to patient improvement. Goldstein and Carlson ${ }^{20}$ have generally criticised day hospitals which operate discharge policies which are conservative.

Nevertheless the day hospital that we are studying has ceased treatment at the end of a year of about $70 \%$ of the patients admitted in that year. There are several ways in which this is achieved, and the range of discharge destinations for day hospital patients reflects the fact that clinical improvement is not the only criterion used. Cases of clinical improvement to the extent of eliminating the need for day care altogether actually account for only i $2 \%$ of discharges, although a further $7 \%$ of patients are considered to have improved to a point where they have become acceptable to transfer to other forms of day care.

By far the largest group of discharges $(5 \mathrm{I} \%)$ is due to deterioration in the patient's condition: $32 \%$ go on to a long-term bed in various parts of the hospital system, $7 \%$ are admitted to beds in the acute sector, $6 \%$ become housebound and unable to attend and $6 \%$ of patients die. A further substantial group of discharges (20\%) occurs because patients and/or relatives refuse to continue attendance. The remaining $10 \%$ of discharges are accounted for by a variety of reasons which are not related to improvement in the patient's condition.

Although comparisons with other studies are difficult due to the different categorisations used, these figures do not seem untypical of statistics on psychogeriatric day hospitals presented elsewhere in the literature. From studies by Blake, ${ }^{21}$ McDonald $e t$ al. ${ }^{22}$ and Goldstein $e t$ $a l .,{ }^{23}$ the average rate of discharge due to patient improvement is about $3 \%$. The day hospital we are studying is thus achieving a higher than average rate in this respect, but this may be accounted for by variation in definition of what constitutes 'improvement'. As for those cases discharged but not accounted for in terms of improvement, Goldstein et al. are alone in using a 'self discharge' category accounting for $20 \%$ of cases. This is the same level as $20 \%$ 'refusals' at the Day Hospital. 
Transfer to in-patient care is not a category utilised by Goldstein $e t$ al. but they do report $20 \%$ discharge rate due to 'deterioration'. Combining figures for 'deterioration' with discharge to in-patient care (on the assumption that such patients have also deteriorated) in the three studies, produces varied rates: Blake $13 \%$, Goldstein $20 \%$, McDonald $49 \%$. This compares with $50 \%$ for the day hospital. The variation may be accounted for by differences in availability of in-patient accommodation and/or tendencies for the day hospitals to retain patients. The latter suggestion gains some support from the way in which the percentage of patients continuing to attend (Blake 67\%, Goldstein $58 \%$, McDonald $50 \%$, the day hospital $33 \%$ ) seems to have an inverse relationship to the percentage of discharges due to deterioration.

There are other studies which present a seemingly more optimistic picture of discharge patterns. For example, Morton et al. ${ }^{24}$ report that $52 \%$ of those admitted to a 'Psycho-socio-geriatric Assessment Unit' were discharged directly back to the community, but of these $5^{2}$ cases $(\mathcal{N}=100), 23$ in fact left for a 'Welfare home'. Pitts ${ }^{25}$ reports that $71 \%$ of patients are discharged 'Back to Community' but this is used as a residual category, the only other specified categories being 'Died' or 'Discharged to Other Hospitals'. Thus here, as in other studies, it is clear that clinical improvement is only one reason for discharging patients.

A policy of active discharge achieves patient flow from a consultant's perspective. However, it creates problems for others, particularly for social workers and relatives who still have the task of providing continued help to the patient at home.

\section{（3） ALTERNATIVE SERVICES}

A third way for the consultant to achieve patient flow is for the hospital to serve as a gateway to other services. Some patients may pass along routes to other forms of day care, particularly to services provided by the local authority (as opposed to the National Health Service), that would not otherwise have been open to them.

The difficulty here is similar to the way in which GPs use of the day hospital sometimes accentuates the problems of hospital staff. A referral from the day hospital to obtain some other form of service provision increases the effective demand for this service and denies it to a social work client who might otherwise have used it. (Although in practice this route is not a busy one, with only $6 \%$ of patients being discharged from the day hospital to social work department facilities). 


\section{(4) USING BEDS}

The fourth approach to seeking turnover in the population of patients entails the day hospital, and particularly the consultant, making use of a small number of beds in Park Hospital in a variety of ways and in close association with the day hospital. 'Short-term beds' entails admission of a patient to Park Hospital for a strictly limited period. 'Shared beds' entails two patients alternating in their use of the bed by week or by days of the week. And 'emergency beds' are beds reserved exclusively for admitting patients taken suddenly ill while actually attending the day hospital. Although not always in conjunction with a day hospital, similar flexible use of hospital beds for planned intermittent admissions has been developed elsewhere in response to shortage of in-patient beds. ${ }^{26}$

From the consultant's point of view short-term beds have clear advantages as he explained,

when you take somebody in here (Park Hospital) for long-term care, although they're elderly that can still be very long-term - years - so if you take somebody into a bed for long-term care that often means that's a bed out of commission for a few years, whereas if you can arrange it for short-term admission you could pass perhaps 15 or 16 people a year through it, that's how I see it.

Such short-term admissions to Park Hospital are used extensively. Approximately $21 \%$ of patients attending the day hospital in any one year are offered this facility. It is a significant means of providing short-term in-patient care when compared with the very limited number of cases successfully referred to geriatric or social work facilities.

Short-term beds may not however offer a solution to the problem as perceived by relatives. They may be reluctant to accept that they have not obtained a long-term bed. This reluctance creates difficulties for social workers and for ward staff who have to deal with dissatisfied relatives. Furthermore, short-term admissions require redefinition of priorities in allocation of beds. These may not be readily accepted by administrators who wish to ensure, on paper at least, that there is maximum utilisation of beds.

From the consultant's point of view, using 'shared beds' has clear advantages. Although this practice is developing, the numbers involved remain very small and the innovation is less significant than the use of 'short-term beds'. However, on this, as on other points, the interests of different staff groups sometimes diverge. For example, the innovation initially met with resistance from a nursing officer on the grounds that the administration would be too complex. With shared-bed arrangements, too, the relatives may be receiving a service which is different 
from that which they had expected. Again social workers and ward staff may have to cope with the resentment which results. The problem with one case was described in an account by a ward sister at a hospital meeting, as recorded in our fieldnotes;

and some of the relatives were getting nasty but she had made it very clear that it wasn't her fault that the patient was in her present situation with only a shared bed. The social worker commented that they didn't have another bed for her. The ward sister continued and said that she had told the relatives to use the official complaints procedure if they weren't happy with the way the patient was being treated. The consultant said he thought the ward sister had dealt with this very well indeed. This was a situation which couldn't be helped. There was a problem in the other shared bed as well. There was no way in which they could do anything at present except note that the patient was needing extra help... The social worker said... that things at home were really bad. The girl had come to the Relatives Group. She was very angry and frustrated and needed to have her complaint heard. The social worker thought she had got a lot out of the group and went away feeling much better... The consultant said that in this case he didn't think the hospital had anything to hide. They could contact MPs and all the rest if they liked.

In such cases GPs, police, and other community services, as well as social workers, have to cope with patients and relatives during the period in which patients are at home.

Also as a part of the arrangements for co-ordinating day hospital places and ward beds, the consultant prefers to retain some vacancies at the day hospital for emergency use. The central point (it is argued) is that only by preserving some flexibility and by tolerating the less than I oo per cent occupancy rate that this entails, is it possible to make any attempt to cope with relatives' holidays, emergencies, and the other unexpected demands on the system. ${ }^{27}$ Thus what may be seen by administrators as a hospital operating at less than its full potential is viewed by hospital staff as being one stretched to its limits.

\section{Day hospital nursing staff}

The second major constituent group of the hospital is the nursing staff. This group includes sister, senior enrolled nurse, community nurse, as well as nurses and auxiliaries. Amongst such staff there is, as amongst other groups, a general agreement that it is highly desirable to maintain a throughput of patients. Like the consultant, nursing staff have strategies for maintaining patient flow.

The first step involves negotiating with relatives about their understanding of the terms of the admission. The following extract from our fieldnotes illustrates this point: 
The hospital is now beginning to be full up. This of course was a position which was anticipated but the crunch has now come and sister and the social worker were discussing what has to be done about it. Some patients have been coming to the hospital now for 7 months or so... Both the social worker and sister felt that there had to be some system initiated by which when patients were admitted to the hospital their relatives were clearly informed that there would be an assessment at such and such a point and the admission would only be for, say three months. Relatives would be told that the patient would be discharged and might then be readmitted but they would then be prepared for the discharge in a way in which they are not at the moment. Of course both sister and the social worker agree that there will be some patients who cannot be discharged at the (say) three-month point, and it would have to be accepted that some cases would be an exception to this general principle; but the point is that relatives would be prepared for the discharge decision as a general rule.

Nursing staff also feel that patients should be very carefully selected to ensure that silt-up does not occur. Austin et al. ${ }^{28}$ and $\mathrm{Pathy} \mathrm{y}^{29}$ have noted the importance attached by day hospitals to selectivity in admissions policies. Also, Goldstein et al. ${ }^{30}$ state in their review of a day hospital that 'Our ability to achieve our goals and to utilize our resources in the most efficient and effective manner depends, to a large extent, on the proper selection of patients.' As one nurse explained in an interview;

it's very easy to take the first ten people that come along, you have to be selective...each person should be assessed, and if you can't do something therapeutically for them, there is no point in filling the place and then you can't admit somebody else who could benefit, and it's a hard thing to say, 'Well, I'm sorry, you're not suitable'. Everybody isn't suitable.

The problem as ever is that the pursuit of sectional interests creates trouble for other groups. Changes in control of admissions to one unit can have far-reaching consequences for the operation of an entire system of service. ${ }^{31}$ Selectivity runs counter to the needs of GPs, who want assistance in providing care for the patients who present them with the greatest difficulties. Selectivity can also be the focus of criticism and resentment from staff of long-term wards in Park Hospital, who feel that they are then left to cope with the residue of 'bad' cases. Some comments from ward staff illustrate this tension:

Maybe I'm trying to put barriers up and all that, because other people have got a better job than I have. (Laughs). We seem to get the heavy end of the stick, I mean it's heavy nursing right enough in our ward. Then you go over to [the day hosital] and see the lovely kind of surroundings and all that and the nice patients sitting there doing a bit of knitting and what have you, and come back to the ward again a wee bit down in the dumps, a wee bit demoralised. I think their grading is pretty high, that's how I say I think they're 
far too selective. I never see anyone that to my mind as I can see there is what I would say a real good going dementia.

However, since $77 \%$ of referrals to the day hospital subsequently become day patients the staff of the day hospital do not appear to be operating a very rigorous selection policy. Many cases are not admitted because of the patients' circumstances, rather than because day hospital staff make a decision about suitability. A maximum of $10 \%$ of referrals are actually rejected by the day hospital staff as being unsuitable. Thus GPs are being relatively successful in advancing their criteria for admission suitability to the day hospital. However, with $32 \%$ of patients going on to long-term beds the day hospital is doing little to divert patients from the ultimate destination of in-patient care although it may be delaying their entry somewhat. This would not be entirely unusual. Greene and Timbury ${ }^{32}$ describe a geriatric psychiatry day hospital thus: 'The role of this day hospital has not therefore been to avoid admission or to expedite discharge or even greatly to postpone admission to long-term in-patient care.' The views of the ward staff are rooted in the very real difference which they perceive between the severity of conditions in the in-patient and day-patient populations, but it is by no means clear that the selection practices of the day hospital staff affect the standards of patients ultimately admitted to the wards.

For social workers the emphasis placed by the day hospital staff on maintaining patient flow increases the task of finding alternative provision for patients in order to prevent admission to the day hospital and to promote discharges. Relatives too may not always perceive the activities of nursing staff aimed at promoting discharges as being helpful. We shall return to this point when we deal specifically with relatives' interests.

In the face of the potential oppositions which arise in reaction to the nursing staff's approach to patient flow, a range of organisational tactics has arisen. Sometimes, groups are able to use the power which they exercise by virtue of their professional prestige, bargaining position, organisational locale or control of resources. Sometimes, power is most effectively exercised by groups entering into alliances, the one with another. It is notable that the consultant psychiatrist is not amongst those whom we listed above as being inconvenienced or perceiving themselves as being inconvenienced by nursing staff. Indeed the interests of consultant and staff are very close on this matter. For in practice the staff at the day hospital and the consultant often share the same problems with regard to turnover.

In attending hospital meetings we observed a number of tactics entailing collusion between consultant and day hospital staff designed 
to ensure continued patient movement. Some cases about which the consultant has reservations regarding suitability are accepted for 'a trial' or a 'period of assessment'. By doing this he recognises the professional expertise of the nursing staff who are largely responsible for this 'assessment' and also holds open the possibility of review and discharge should admission prove to have been ill advised. The consultant may agree to admit a case but hold open the possibility of the patient being discharged to other facilities in the future. The number of days per week which the patient is allocated can be limited. Any case setting a potential precedent is treated cautiously. Admission criteria are flexible and, although this does not often happen, on occasions cases which might otherwise be considered suitable may be refused admission if staff are anxious about imminent silt-up. Another strategy adopted jointly by consultant and staff when places are under heavy demand is to delay the decisions on some patients and thus regulate the rate of admission. Finally there are a variety of tactics to reduce frequency of attendance and thus edge patients towards the door. For example, in this extract from our fieldnotes on a hospital meeting;

Sister asked if she could reduce Mr I's attendance to once per week. The consultant agreed. It was also agreed that they should reduce Mrs Q's attendance to once per week, working towards her eventual discharge. The consultant said, Yes, of course, they must work towards discharge.

The idea that patients should 'work towards' discharge is used by staff in their direct dealings with patients who are encouraged to accept the view that patients should themselves be anticipating discharge as a normal feature of the hospital's services. On occasions, too, the fact that the consultant can 'keep tabs' on a patient after discharge, review the case and readmit if necessary, eases decision making with increased turnover in view.

\section{General practitioners}

The interests of general practitioners (GPs) are amongst the most crucial to the operation of the day hospital, since the accepted admission pathway and the one followed by the vast majority of patients is via their GP to the consultant in charge. Only $12 \%$ of patients arrive in any other way. The GPs' interests in maintaining patient flow are primarily concerned with their problems of obtaining services for patients who are proving troublesome. As Shulman and Arie $^{33}$ have shown, in their analysis of the reasons for the fall in admission rates of old people to psychiatric units, it is probably becoming more difficult 
for demented people to be admitted to psychiatric hospitals. For many GPs psychiatric cases represent a severe burden. Pressed by relatives, and their own concern for the patient, the GP's major task often becomes the search for some form of hospitalisation. Carney, Ferguson and Sheffield ${ }^{34}$ have described the burden imposed upon GPs by these patients in the form of calls and consultations. Williams ${ }^{35}$ has reported the variety of headings that GPs use to describe such patients in attempts to gain access to hospital facilities. From this point of view, the day hospital represents a new and welcome additional point of referral. As one GP explained:

I think speaking as a GP outside I can see the benefits greater than I can from the inside. Before there was very little I could do for psychogeriatrics.

Jones and Munbodh ${ }^{36}$ report that $65 \%$ of GPs referring patients to one day hospital for the demented elderly described patients' attendance as reducing demand for GP care and treatment.

The pressure which GPs exert on the system is clearly demonstrated in the hospital meetings. Although no GP actually attends these meetings, other staff frequently quote GPs' letters and telephone calls, and refer to the fact that GPs are under pressure. The following examples are from our fieldnotes.

The GP in his letter had said that the patient was demented, but the consultant suggests that it is more a case of agitation. He read out an excerpt from the GP's letter in which the GP said that he was under strong pressure from the matron of the home to have her removed.

She had originally been accepted as a patient at the day hospital not because staff thought they could help her but because she had great nuisance value over a long period of time at her local GP group practice.

Of course, the type of case for which hospital service is most welcomed is that which the GP regards as the most severely ill, most unlikely to be able to remain at home with relatives, even with domiciliary support, or most likely to present some 'crisis' through nocturnal wanderings or whatever. Yet as an administrator explained, it is precisely this type of referral which causes problems for patient flow at subsequent points in the system. Referral of one type of patient at one stage may silt up the system at another:

GPs had very fixed ideas about the sort of patients that were suitable for [the day hospital] and invariably a lot of these patients were, obviously, in the more advanced stages of mental deterioration and therefore the scope to help these patients was limited. 
Certainly staff see GPs' referral practices to the day hospital as conflicting with their interests, and such conflicts as endemic to the system of psychiatric care. In one interview a nurse described this problem:

(GPs) want the patient removed from the community and put into a ward, because that takes the onus off of them and they're safe and secure in a hospital ward, and you are always going to come up against the problem of that because you are going to try the opposite and reverse it and keep the patient in their own home and the GPs wouldn't like that.

These tensions reflect very real differences in the criteria which GPs and hospital staff apply when considering possible admission. The GPs' requirements are for facilities which will help them cope with any elderly patients who are making, in their opinion, excessive demands on their time and energy. It is this need which brings them into conflict with day hospital staff who feel that they must retain selectivity in order to avoid silting up their part of the system. However, these conflicts do not always emerge explicitly (in practice the vast majority of referrals are accepted). As we are explaining throughout this paper, each group is heavily dependent upon several other groups for the accomplishment of its day-to-day work. We have noted that there is widespread acknowledgement that this work should be conducted in accord with the overall aims of 'patient flow'. A group risks endangering co-operation with others and risks a challenge by others to its own image of success if it casts aspersions upon the intentions of other groups. So typically nurses describe GPs' activities as the result of failure in communication and understanding, and not as a direct challenge to the successful functioning of the hospital. As one senior nurse commented: the trouble really has been caused by GPs not really understanding what the unit's about and thinking that we can just accept people willy nilly sort of thing...We do have to discharge an individual after a period of time, something which I think the GPs still haven't quite got to grips with, I think they imagine that once they are in, and until there's a marked improvement, that the patient will remain with us, but this is not the case...I would like to see us being able to - educate, shall we say, the GPs a bit better.

This is a very familiar tactic within organisations for diffusing ideological or interest group conflict and maintaining a sense of coherence in the system as a whole. $^{37}$

\section{Ward staff}

Park Hospital is the larger institution in the grounds of which the day hospital has been built. We did not initially think of staff in Park 
Hospital as a constituent group of the day hospital. But links between the two hospitals have developed in the pursuit of patient flow objectives and in several ways this group of staff are an intrinsic part of the operation of the day hospital. The two sets of buildings are very close. Park Hospital has psychogeria tric wards. Some senior nursing staff have responsibility for nurses in both hospitals. The consultant in charge of the day hospital places is also in charge of some beds in Park Hospital. From the perspective of the staff of Park Hospital, the day hospital is seen as a potential supplement to their resources and an aid to the discharge of long-term patients. As Wadsworth et al. ${ }^{38}$ Whitehead and Mankikar ${ }^{39}$ and Goldstein and Carlson ${ }^{40}$ report, many day hospitals for the elderly operate similarly in close conjunction with in-patient facilities.

The use of the day hospital as ward staff would wish conflicts with the aims of other groups. There is conflict with the day hospital staff. A strategy which would enhance patient flow out of in-patient wards would generate problems for the day hospital by blocking that part of the system if patients did not move on. An administrator explained:

initially they [in Park Hospital] wanted us to have patients in the ward over... really what they were looking for was making us an extension of diversional therapy, which would have been no good at all just bringing the patients in here and [the day hospital] doing something... but that would have snowballed if you know what I mean, we would have ended up as an extension of diversional therapy and that would have been all.

Similarly, for the consultant psychiatrist, admitting someone as an in-patient to the day hospital can only be advantageous if there is a definite prospect of discharge and freeing an in-patient bed. A nurse noted that without discharge the hospital is left with one patient effectively occupying two places:

but we [in Park Hospital] still thought it could have been used in the event of there being places, y'know for example, there's not always 25 in every day and on the days when they weren't up to their full total possibly a few patients from the wards could go over but [the psychiatrist] didn't agree with this outlook at all. He has stated quite categorically that unless there is some hope of that person living outside the hospital, wherever, he doesn't see that they have a place in the day hospital.

In practice, the day hospital is not playing any major role as a stepping stone for outward movement of patients from Park Hospital. For example, in one year there was only one attempt, and that unsuccessful, to use the day hospital to discharge a long-term patient.

As the nurse that we quoted above implies, the consultant has made 
a policy decision about the role of day hospital places in discharges from Park Hospital. Although there is not often negotiation on this point there are examples in hospital meetings of cases where Park Hospital staff press for the discharge of recent admissions whom they consider to be inappropriately placed. In the case described in the following fieldnote the patient had previously attended the day hospital, but had been admitted to a bed in Park Hospital. The ward charge nurse is now suggesting a trial period at home with a view to eventual discharge, with day hospital support.

The nurse, however, stuck to her guns and returned again to the question of the patient. The nurse put it this way. 'I am sorry to keep pushing this patient, but he had made a request to go home and he is the best of the patients that we have on the ward' and so the nurse suggests that perhaps the meeting needed to reflect on what they might be able to do with the patient. However, the social worker feels it necessary to point out that ... the patient's wife would go along with any demands that were made upon her but would not in fact be able to fulfil the demand by being able to accommodate her husband when he does return home. Thus, it would be more difficult to help the family and to accommodate the patient since there would have been a trial run of his going home which is what he seemed to want so much and that would fail and that would lead to all kinds of difficulties and strains for the family. At this point the consultant intervenes by almost thinking aloud, 'How would it be if suppose that when he goes home his diabetes gets bad and he might flare up. We could give him a weekend at home and then persuade him to come back.' The social worker says this might be a problem because he won't want to come back, it is quite true, but on the other hand, she suggests perhaps the family won't be able to bear any more, so that we need to move rather tenatively, 'we need to see how things go'. The consultant then recapitulates from what has been said and attempts to draw some conclusions. He says, 'Although he is good in the hospital, the problem is in the home and the family where he might behave differently and this arena is the important one'. The social worker says that she would like to speak to the family first, before she announces any plans in respect of the patient. The nurse again reiterates her apologies, she says, 'Sorry to go on about him, but he is the best patient in the ward'. [Emphasis in original note.]

The outcome in this instance is ultimately determined by the fact that the consultant supported the social worker in resisting ward staff pressure to obtain a discharge from Park Hospital. We noted above that in spite of significantly different interests, groups are in various ways heavily dependent upon each other for co-operative activity. This would explain why the difficulties which a discharge might create for the social worker outweighed in the consultant's mind the arguments of ward staff in favour of discharging the patient. These were arguments which the consultant might otherwise have welcomed as 'facilitating patient flow'. In a contrasting case, Park Hospital staff were more 
successful in obtaining a discharge after the social worker was pressed into offering assistance of accommodation from the social work department. This move fulfilled the needs of the ward staff in moving out a patient they considered inappropriately placed and the needs of the consultant by releasing a short-term bed for his further use, and avoided the threat of filling a day hospital place permanently.

We have here very specific instances of the general point that we are making throughout this paper. Much of what takes place in connection with the movement of patients around the system can be explained as the pursuit of parochial interests cast as organisational goals.

\section{Social workers}

The social worker, as a member of the team of day hospital staff, is involved in making decisions about admission and discharges to an extent which is not always evident in this type of setting. ${ }^{41}$ She accepts the general principle of the need to maintain patient flow in the light of particular patient needs. However, for her more than for other staff this has to be tempered with concern for the needs of the family unit. For in practical terms it is the existence or not of a family capable of looking after the patient that largely determines the nature and possibility of discharge 'to the community'. Because such practical concerns are not uppermost in the minds of other staff who see themselves primarily as members of a hospital, a medically oriented view may be rather different. Peach and Pathy, ${ }^{42}$ for example, have noted in the context of geriatric care that the traditional medical history and examination pays no significant attention to the social support a patient needs. A social worker made the point thus:

Well a social worker offers a wider view of the patient. I think that's putting it in a nutshell... First of all $I$ think the medical team would see the social worker as a resource person, I think that is part of it but it is not all of it, in fact it's not anywhere near what the social worker can offer to the team... They can be quite educative in widening the medical team's point of view. The medical side is usually very narrow, I don't mean they're narrow people, just that they see it as a medical problem, bring them in, do a thing, cure, home or whatever to provide and that's it... I thought that they had to understand what a social worker was, now that is not an easy thing to do without causing a lot of resentment.

Although differences in perspectives of medical and social work staff reflect differences in training and professional attitudes, they reflect too the very different practical interest of different groups of staff. The one is primarily concerned with tasks within the boundaries of the day 
hospital, the other with tasks without. Relatives' support for discharged patients is a major part of the social worker's day-to-day work. So some resistance to discharge on the part of the social worker reflects her concern about limited family support, which largely accounts for the absence of any significant number of cases of successful discharge of long-term Park Hospital patients.

Naturally, such a pattern works against the interests of consultant and day hospital staff as well as the ward staff. Potentially therefore the social worker is in an isolated position, with interests quite distinctly different in key respects from all other staff groups. This potential isolation is accentuated by the fact that the interests of her own social work department are also distinctly different from those of the hospital system. But an isolated position is intolerable for any group within the hospital because, as we have noted, each is heavily dependent upon the co-operation of others. Thus the social worker must achieve a modus operandi in which the practical constraint of having to arrange relatives' support is modified by a co-operative approach towards achieving the goals of the most powerful of the day hospital's staff groups. The social worker must mediate between the interests of the hospital and those of the social work department. She explained this in interview:

When you're a social worker in this kind of setting it's sometimes difficult to define where you are, who is it I work for and who is my client. Is it the patient, is it the hospital, is it the relatives or is it the social work department? Who am I trying to help? Sometimes when you have the traumas and the dramas of the job then you're stuck right in the middle, and you really have to try... so I try very clearly to define in my own mind whether I am trying to please the... I would never try to 'palm off' if you like, a psychogeriatric patient in a Part IV accommodation, one, because I think that would be wrong, but two, I certainly think it would be wrong for the unit as a whole because if I say all sorts of things and I persuade them, as you can do at times, to take somebody who is totally inappropriately placed, that would please the consultant and that would please us here as well as at the unit but it will not please them (i.e. Part IV staff) as time goes on and then I won't be believed the next time, so there are things like that that are very frustrating.

In practice the bargaining which ensues does not lead to substantial numbers of patients being discharged from the day hospital to social work department facilities. Only $6 \%$ of patients leave the day hospital in this way, and only a very small proportion of referrals dealt with by the day hospital is actively re-routed from Health Service to social work provision. However, a variety of short-term co-operative arrangements between the services has occurred and the negotiations giving rise to 
these are regularly reported in our fieldnotes. For example, one patient, $\mathrm{Mr} \mathrm{A}$, was coming short-term from the care of his relatives to take up a hospital bed. In order to make a bed available, $\mathrm{Mr} \mathrm{B}$ was being discharged from the hospital to local authority Part IV accommodation for a similar short period but under the clear understanding that he would be re-admitted to the hospital at the end of that period and that the current move did not represent a termination of any ' psychogeriatric' designation. On other occasions the bargaining involves the social worker having to run counter to the interests of the day hospital staff by persuading them that other facilities are also suffering from pressure of demand.

\section{Relatives}

Although relatives are not ever present at hospital meetings their influence on decision making is considerable. We have described their impact upon the work of the social worker. Relatives' interests also have an effect on the psychiatrist's decisions about the form of treatment to which patients should be allocated. Rathod and Vandrey ${ }^{43}$ report that relatives' attitudes towards patients' disturbed behaviour are a major factor in the decision as to whether to admit the patient to in-patient or day care. Bergmann et al. ${ }^{\mathbf{4}}$ report family support as the most important factor in retaining the patient in the community. Cosin ${ }^{45}$ goes so far as to argue that the social status of the family is more influential than the psychiatric status of the elderly patient in determining admission. Although we should be careful in treating relatives as a homogeneous group it is because of their influence that we consider them to be a significant constituent party to the day hospital. ${ }^{46}$ In the day hosital that we are studying relatives provide some measure of support for $83 \%$ of patients admitted, with $54 \%$ of patients actually living with their spouse or other family members.

The extent of the intervention required by relatives varies according to the condition of the patient. Many relatives expect and often experience a progressive deterioration, and their interest is therefore in obtaining a service which will provide relief on a long-term basis. Ultimately, for many relatives, the need is for the patient to be admitted to a permanent hospital bed. This does not always coincide with the views of the medical service. For example, the efforts of relatives to acquire beds create problems for the GPs and other community-based services. In cases where relatives want a more extensive service than is being provided hospital staff may have difficulties in coping with dissatisfied relatives. 
Many studies of client use of services stress the relatively powerless position of client groups. ${ }^{47}$ In many respects the relatives of psychogeriatric patients are no exception. Nevertheless, relatives as well as staff employ a range of tactics in order to gain their goals, and this leads to conflict.

From the staff point of view much of the conflict is seen as communication failure. As we have already mentioned, denial of conflict is not uncommon in organisations. The practical solution, as staff see it, then lies in a fuller explanation to relatives of the real nature of the situation. For example, relatives do not share the hospital's perspective on discharge. The process may appear insensitive or incomprehensible. Staff are aware of this. The following fieldnote on a relatives' group illustrates the point:

When the social worker explained that there was a system of six-weekly reviews, the relatives were very worried about the patient being returned home because they couldn't cope with the problems. In spite of some glossing to the contrary on the part of social worker and sister it seemed generally assumed that the basic condition of the patient would not have changed and that therefore the problems to be coped with on the part of the relatives would be the same.

Discharges must therefore be handled carefully. Any violent reaction from relatives causes the social worker considerable difficulty. One such instance was described thus in our fieldnotes on a hospital meeting.

Apparently there was a considerable problem about one patient being discharged where the relative was told only a day or two before about the discharge and the social worker then got a lot of flak from the relative who complained about the way that 'you sit up there making your decisions' and 'don't know what is really going on down here' [i.e. in the home].

So the staff's attempts to obtain agreement from relatives on the way in which they are handling a case are not always effective. Where this fails staff may partially respond to relatives' demands by providing a service of a less extensive nature than the relatives really require. Shortterm admissions are the most obvious example of this ploy. As one member of staff explained:

I think that's the point of the exercise, to keep the relatives from actually wanting a bed or we would be in trouble.

Staff are aware that this tactic frequently does not meet the needs of relatives.

Relatives also pursue their own ends. They do control access to much information about the patient and this they may seek to use for their own purposes. The following discussion taken from our fieldnotes 
illustrates one strategy which relatives may use to gain admission for the patient:

One patient has become very aggressive. The consultant wondered whether relatives had been hiding the aggression on admission. Other staff often felt that relatives did do that. Relatives were under the impression that, as with admittance to a local authority home, if they portrayed the old relative as being troublesome then they would not be admitted. On interview they therefore sometimes went out of their way to present a good picture 'but we are just the opposite'. It sometimes therefore turned out that in fact the patient was rather more troublesome than the relatives had pretended.

However, since relatives are handicapped through an imperfect knowledge of the operation of the hospital, they cannot always tell what information is likely to influence decisions in what way.

Relatives also wield some power in their ability to constantly harass the consultant psychiatrist and other staff. One extreme example of the conflict between relatives' interest in obtaining facilities for the individual patient and those of the hospital staff in maintaining patient flow was illustrated when the consultant described the difficulties experienced in attempting to institute a system of short-term beds. From his point of view it was necessary to be aware of this conflict and to take steps to protect his position.

In this sort of work you're always looking over your shoulder at some relative who's going to complain at a high level; well, that's all right, if you can show that you've done everything possible: but, for example, if I've got a female vacancy tomorrow and said, 'let's leave that till we line up a short-term patient' and in the meantime a tragedy occurred and there was some sort of enquiry then I feel that I would be very vulnerable.

Relatives may also harass the consultant when, having obtained admission of a patient to a short-term bed, they decide that it is not in their interests to have the elderly person returned home. We recorded one such case in the following discussion:

Sister reported that Mr X's wife had said that she had been advised not to have him back... Mrs X says that she had 'double hernia' (this was something that she repeated at the last Relatives Group). She had also told sister that $\mathrm{Mr} \mathrm{X}$ abused her and she was generally very upset. The consultant asked who it was that has 'advised her not to have him back'. Sister said this wasn't clear but she imagined it might be the GP, according to Mrs X. Consultant:

'Oh no! This would not be so...it's amazing how people manipulate the situation [perhaps for my benefit]'... The consultant then elaborated a little on the way in which he encountered patients and relatives who played off one professional against another. Sister, the consultant and nurse all agreed that, 'They take up the short term beds but then the barriers come up' [i.e. relatives 
say at first that they want a short break but once they've got rid of the patient they don't want to take them back].

Most often, conflict between relatives and staff is muted. Open disagreement occurs only occasionally. When relatives 'go too far' then consultant, social worker and nursing staff assume considerable solidarity in the face of a threat to their mutual authority and control. Again, a fieldnote on a hospital meeting provides illustration.

The consultant asked the social worker if she felt the problems at home were being exaggerated. The social worker said that the wife was under a great deal of strain and the patient would have been a candidate for a bed very soon. She went on to say though that the way this patient had to be admitted really sticks with her, that the relatives managed to pressurise them so much...The consultant then went on to outline what had happened in this case. The son had phoned and gone into a tirade after which he hung up. He was threatening to go to the Press about the patient not being admitted as an in-patient. The consultant felt that the Health Board might not accept the decision of not admitting the patient because of the redecoration. The nursing officer asked if the whole fuss that the son had created had been a major factor in deciding to admit the patient. The consultant admitted that this was the case along with the fact that they were in a weak position because they had in fact had vacancies. Discussion continued and the crux of the staff's concern about relatives exerting pressure in this way eventually emerged in comments by the social worker. This man could go on to tell others that this is how the bed had been acquired and this could lead to widening rumours... The social worker commented that, 'we learn as we go along'. In this case they had acted but they could now look at how they could better deal with this in future. She felt they had to teach this man that you cannot behave in this way. The community nurse commented that 'this manipulation does go on'.

\section{Conclusions}

We began this paper by describing a problem in evaluative research. Difficulty arises because different groups within health and welfare organisations typically define 'success' in different terms. Even when agreed upon some broadly defined criterion they tend to pursue it in different ways, often creating 'trouble' for each other as they do so. We have described this process in one particular context - a new psychogeriatric day hospital - and with respect to one particular objective that the hospital should achieve a turnover in its patient population and avoid silting up. We have dealt with the perspective of consultants, day hospital nurses, general practitioners, ward staff, social workers and relatives. Our account shows how difficult it it to draw evaluative conclusions when each of the plurality of perspectives is taken seriously. We wish to assign credibility to organisational members rather than ride 
roughshod over major interests by selecting one - or even a select few - perspectives to serve as the evaluative measure.

Now it is not, of course, new to observe that the exercise of evaluation has its problems. Weiss made the point a decade ago:

The evaluation question sounds simple enough in the abstract... But what looks elementary in theory turns out in practice to be a demanding enterprise. Programs are nowhere near as neat and accommodating as the evaluator expects. Nor are outside circumstances as passive and unimportant as he might like. Whole platoons of unexpected problems spring up. ${ }^{48}$

But in spite of the persistent nature of these problems there is little evidence that any solution has been advanced that commands widespread support amongst social scientists. Goldberg and Connelly can only conclude an extensive collection of reports on Evaluative Research in Social Care with the comment that:

The heated discussions of the pros and cons of the use of different methodologies in evaluating outcomes seemed to signify a search for the most relevant approach according to the state of theoretical knowledge, the state of the art of intervention techniques, and the constraints of the field setting. There was agreement that evaluation of social care demands many different approaches. ${ }^{49}$

This seems to be a polite way of saying that evaluation research is still in a state of considerable disarray.

Certainly there can be little doubt that strategies of evaluation in studies of health services for the elderly are notably underdeveloped. Kelma ${ }^{50}$ has pointed to this state of affairs and has enumerated several factors which he believes account for it. First, the evaluation of social and medical care has failed to address generic issues, remaining sporadic and non-cumulative, and predominantly local in the applicability of its findings. Second, support has remained tied to particular action programmes. Third, in its results, such research may be threatening to administrators, clinicians and planners. Fourth, 'evaluation and evaluation research suffer from a lack of consensus, in meaning, scope and purpose'. For example, there is no agreement on who should be responsible for the research and where they should be positioned organisationally. Finally, there are methodological problems in the use of controls, in the fact that the programme being evaluated is itself often 'flexible', and in the argument that, 'no one set of measures of impact can be validly held to be the criteria of the program's objectives'.

It is this final set of problems which have so far most influenced the conduct of the project which this paper, in part, reports. As we explained in an earlier statement: 
The study originated as an 'evaluative' exercise but the distinctive features of the research have derived from the fact that it is apparent that the most usual 'rationalistic' ways of thinking about evaluation in health care may have major weaknesses in this context. This is because there are a range of different views about specific service objectives, criteria of success and defined relevant outcomes, because the controls of the 'experimental method' are not possible and because much often remains to be done in describing the precise nature of the service itself. ${ }^{51}$

In this paper we have pursued some aspects of this general point in relation to the particular matter of patient turnover in a psychogeriatric day hospital. We have taken the view that an attempt to disentangle the meanings and pursuit of 'turnover' is an intrinsic part of the evaluative exercise.

Our attempt to unravel these meanings and the operational strategies which are consistent with them has involved a good deal of detailed description, both of the perspectives of different groups and of the workings of the institution. This detail has, cumulatively, displayed characteristics of the hospital which are of central importance to questions of an evaluative kind. The picture of the day hospital which emerges is one of a pluralistic and segmented institution. The meaning of 'successful patient flow' for each party is heavily contextually determined, and the parties' success in expressing that meaning in practice varies with the degree of opposition that they meet when encountering the gambits of those who construe and pursue the hospital's successes in other ways.

Thus, for instance, GPs have few referrals refused, but their referrals are not encouraged as much as they might. Consultants have an additional resource but have experienced no significant easing on the shortage of in-patient beds. Day hospital staff have ensured, largely through influencing discharge rather than controlling admission, that patients go as well as come, but ward staff have largely failed to improve the in-patient discharge rates through day hospital auspices. The position of the social worker has minimised conflicts which might have arisen between the different health and social work perspectives, yet few patients flow freely between the facilities of health and social work. Relatives wield considerable potential power yet seldom exercise it as effectively as they might. These are examples of the kind of observations that we have made throughout the paper in our attempt to link the problems of an organisation as perceived by members to the performance of that organisation as a service institution. Our claim is that such material constitutes evaluation. 
So the line of argument is this. The workings of the hospital resemble the processes of political pluralism. As summarised by Hall et al. in the context of social policy studies this process is described thus:

The policy process can be regarded as pluralistic in two senses. First, it exhibits diversity in a visible, structural sense; many different institutions are involved. Second, and more important, the policy process can be characterised as plural in practice. The strutural diversity is reflected in the range of values, interests and viewpoints that can be detected in much policy-making. ${ }^{52}$

In the work of Hall et al. this approach is used at a macro level to describe the interaction between institutions within a political system. Our proposal is that the approach may be used also at a more micro level to describe the interaction between groups within an institution. Thus in adapting Hall et al. ${ }^{53}$ we suggest that the hospital functions broadly in accord with the following propositions. First, it is not contained within a single centrally co-ordinated system, at least so far as the flow of patients is concerned. Second, a range of groups can and do bring strategies for patient turnover to life. Third, these groups differ in their interests and the tactics which they espouse. The patterns of power, authority and influence within the institution are not welded into a simple hierarchical structure. Fourth, nevertheless not all interests or interpretations can be brought into play with equal chance of success or with any chance at all. This is because, fifth, real differences of power are apparent although, again, power is by no means unidimensional. Taken together these perspectives do not significantly diverge from the picture of a psychiatric hospital given by Strauss $e t$ al.

The model presented has pictured the hospital as a locale where personnel, mostly but not exclusively professionals, are enmeshed in a complex negotiative process in order both to accomplish their individual purposes and to work in an established division of labour - towards clearly as well as vaguely phrased institutional objectives. ${ }^{54}$

It is the pluralistic character of the hospital which is out of line with that straightforward requirement of simple evaluation - namely a clear measure of 'success' of the organisation's performance. That is why, as Weiss explained, evaluation in this field is seldom as simple as it first appears. And the point we are making is that the plural character of the institution is actively displayed when we acknowledge that evaluation is not as simple as it first appears. A most constructive approach, then, is to revise our notions of what shall count as the evaluative exercise. The alternative is merely to adhere to a rigid model of the way in which success is pursued in organisations. But then we encounter methodo- 
logical problems of our own making because the processes of patient turnover (or whatever) are not the coherent, rational processes upon which we had hoped our evaluation would rest. ${ }^{55}$

So if we take multiple meanings seriously in service organisations, if we seek to display them in empirical detail, and if we describe also the associated tactics of interpretation, then, it seems, we give the lie to the fond hope that a simple evaluation is ever possible. What emerges is a pluralistic account which is bound to show that on some criteria, given some meaning and pursued by some group with some influence to some effect, the hospital, or whatever is in some sense successful. In other senses and from other perspectives it is not. In short, an answer to the evaluative question is complicated, lengthy and detailed and we must set it out as fully as we can. But rather than proving to be an embarrassment, a pluralistic framework now serves an invaluable purpose; it helps us to structure this account.

Finally, we should explain that we do not expect this approach to evaluation to be welcomed either by social scientists clinging to a consensus model of organisational functioning, or by hard-pressed administrators seeking straightforward guidance on the success or otherwise of a new venture, or by professionals reluctant to admit that theirs is not the only way of looking at the world. Yet we believe that some of the potential criticisms of a pluralistic approach to evaluation are misplaced and some of the apparent attractions of 'straightforward' evaluation spurious. We conclude the paper, then, by listing six points on which the approach we have suggested seems to have some advantages.

(I) It might be thought trite to conclude, in essence, that in some ways the hospital is successful and in some ways it is not. But that seems no less trite than to conclude, as most evaluative studies do, that the institution is not as successful as it would ideally wish to be. The fact that organisations fall short in their achievements of utopian ideals has been described so often that little is learned by showing just that, yet again.

(2) The important point is to be able to show why particular failures or successes occur. We have referred to Weiss's comment that an inability to do this is a frequent weakness in evaluative research. Pluralistic evaluation, however, says a good deal about why some outcomes but not others occurred.

(3) This opens the way to proposals for change. There is little point in knowing that a service ranks high or low on some criterion, however supposedly 'objective', if we cannot conclude from the analysis how the performance can be improved. 
(4) It is important to remember that even high levels of success may have significant costs in terms of unanticipated consequences. Many evaluative strategies have no way of detecting these costs. Although the strategy that we have suggested is by no means foolproof on this count, its more diverse approach means that it stands a greater chance of revealing the unplanned as well as the planned outcomes of innovation in service provision.

(5) There is the question of implementation. Any recommendation for improvement will depend for that implementation, at least in part, upon the attitude of agency members to the evaluation exercise. Many evaluations are dismissed because they do not use the criteria which influential groups in the agency themselves employ. While pluralistic evaluation may seem complex and uncertain in its use of multiple criteria, it cannot be dismissed for failing to take at least some account of the perspective of any significant group of particpants.

(6) While much 'objective' evaluation seeks to remain politically neutral but in practice becomes hopelessly embroiled in the politics of the organisation being studied (even if the evaluators do not always realise what is happening), pluralistic evaluation stands some chance of remaining 'independent' and 'neutral' by having taken sympathetic account of as many perspectives as possible. The irony is that by taking the political process of the agency seriously there is some chance that the politics of evaluation will itself be simplified. As we have argued throughout, little is to be gained by pretending that the processes of pursuing and evaluating success are simpler than they really are.

\section{NOTES}

I For the most recent overview of research on this theme in the context of services for the elderly see Goldberg, E. M. and Connelly, N. The Effectiveness of Social Care for the Elderly: An Overview of Recent and Current Evaluative Research, Heinemann, London, I 982 . In spite of much work on the problems of evaluation, a difficulty - which is essentially some form of the difficulty that we describe here - constantly reappears. Goldberg and Connelly state in summary:' The evaluative process starts with the identification of aims, goes on to the definition and assessment of needs, the description and monitoring of input and moves on finally to the measurement of outcome' (p. 37) [italics added]. In this article we describe how we are confronting the first stage of this process in research. (Although by the end of the paper we shall be led to concude that aims, assessed needs, inputs and outputs are by no means as separate or sequentially related as Goldberg and Connelly seem to suggest.)

2 Throughout the paper, such figures are drawn from the pilot study of the medical records, mentioned in the text. There may have been changes over time but we have no evidence to suggest that this would affect the general points that are made in this paper. 
3 For comparative accounts of day hospital and other day services for the elderly and elderly mentally infirm, see Brocklehurst, J. C. and Tucker, J. S. Progress in Geriatric Day Care, King Edward's Hospital Fund for London, I980; and Tibbitt, J. E. and Tombs, J. Day Services for the Elderly and Elderly with Mental Disability in Scotland, Scottish Office, Edinburgh, 198 r.

4 Smith, G. Some Problems in the Evaluation of a New Psychogeriatric Day Hospital, in Taylor, R. and Gilmore, A. (eds) Current Trends in British Gerontology, Gower, Aldershot, 1982, 204-2 16.

5 'Patient flow' is not the only criterion of success used within this hospital. We are reporting upon other aspects of the work of the hospital elsewhere. See Smith, G., Cantley, C. with the assitance of Ritman, V. Pluralistic Evaluation: A Study in Day Care for the Elderly Mentally Infirm. End of Grant Report Submitted to the Scottish Home and Health Department (mimeo), Department of Social Administration, University of Hull, 1983. Smith, G., Cantley, C. with the assistance of Ritman, V., Day Care Made Simple. Health and Social Service Journal (9June 1983). Cantley, C. and Smith, G. Social work and a relatives support group in a psychogeriatric day hospital: a research note. British Journal of Social Work (forthcoming).

6 For examples see Pathy, M. S. Day hospitals for geriatric patients. The Lancet, ii (6r9), (1969), 533-535. Baker, A. A. and Byrne, R. J. F. Another style of psychogeriatric service. Brit. 7. Psychiat. 130, (1977), 123-126. Cross, K. W., Hassall, C. and Gath, D. Psychiatric day-care: the new chronic population? Journal of Preventive Social Medicine 26, (1972), 199-204. Martin, A. and Millard, P. H. The new patient index - a method of measuring the activity of day hospitals. Age and Ageing 4, (1975), I 19-1 22. Green, J. G. and Timbury, G. C. A geriatric psychiatry day hospital service: a five-year review. Age and Ageing 8, ( 1979$), 49-53$.

7 Data on this project were collected under the usual conventions of research confidentiality and the protection of individual respondents. It is not possible in this paper to infer with certainty the identity of respondents (even though reavers familiar with the research context may feel that they can). In ways which are not significant to the arguments of the paper some details have been deliberately falsified to ensure that this is so.

8 Blake, D. H. A day hospital for geriatric patients: the first twelve months. The Medical Joumal of Australia ii (18), (1968), 802-804.

9 Op. cit.

Io Silverman, W. H. and Val, E. Day hospital in the context of a community health program, Community Mental Health Journal I I, I, (1975), 82-9o.

II Op. cit.

I 2 Goldstein, S., Sevriuk, R. N. and Grauer, H. The establishment of a psychogeriatric day hospital. Canad. Med. Ass. J. 98, (18 May I968), 955-959.

13 Irvine, R. E. Physiotherapy and the Geriatric Day Hospital. Physiotherapy, 55 (9), (1969), 352-357.

14 Op. cit.

15 For example, Marsden, C. D. The Diagnosis of Dementia, in Isaacs, A. D. and Post, F. (eds), Studies in Geriatric Psychiatry. Wiley, Chichester, 1978, pp. 95-I 8.

16 This is not to imply that patients are discharged in a way that could be adjudged clinically premature. Such an assessment is not a part of our evaluation of the hospital.

17 Op. cit.

18 Op. cit.

19 McDonald, R. D., Neulander, A., Holod, O. and Holcomb, N. S. Description of a non-residential psychogeriatric day-care facility. The Gerontologist, Winter, Part I, (I97I). 
20 Goldstein, S. E. and Carlson, S. Evolution of an active psychogeriatric day hospital. C. M. A. Joumal II (1976), 874-875.

21 Op. cit.

22 Op. cit.

23 Op. cit.

24 Morton, E. V. B., Barker, M. E. and McMillan, D. The joint assessment and early treatment unit in psychogeriatric care. Geron. Clin. 1o, 2 (1968), 65-73.

25 Pitts, J. Y. Psychogeriatric care: a programme for hospital treatment. Nursing Times 70, 35, (1974), 1342, 1343 .

26 Erickson, R. C. and Backus, F. I. Symptom severity and day hospital admission. Hospital and Community Psychiatry 24, 2, (1973), 102-104. Robertson, D., Griffiths, R. A. and Cosin, L. Z. A community-based continuing care program for the elderly disabled: an evaluation of planned intermittent hospital readmission. Joumal of Gerontology 32, (1977), 334-339.

27 Organisational strategies for achieving patient turnover are important, but we do not mean to imply that the Consultant's manoeuvres are purely tactical. He also exercises very considerable power rooted in his professional and legal position as consultant-in-charge of the hospital.

28 Austin, N. K., Liberman, R. P., King, L. W. and DeRisi, W. J. A comparative evaluation of two day hospitals. The Journal of Nervous and Mental Disease 163, 4 , (1976), 253-262.

29 Op. cit.

3o Op. cit.

3 I Silverman and Val, op. cit.

$3^{2}$ Op. cit.

33 Shulman, K. and Arie, T. Fall in admission rate of old people to psychiatric units. British Medical Journal (2 I January I978), $156-158$.

34 Carney, M. W. P., Ferguson, R. S. and Sheffield, B. F. Psychiatric day hospital and community. Lancet, (1970) 1218-1220.

35 Williams, R. G. A. Innovation in community care and general practice: a study of interpretations of a day hospital. Social Science and Medicine, I4 A, (1980), 501-510.

$3^{6}$ Jones, I. G. and Munbodh, R. An evaluation of a day hospital for the demented elderly. Health Bulletin 40, 1, (1982), 10-15.

37 For a general discussion of this and related processes see Thompson, K. Organisations as constructors of social reality, in Salaman, G. and Thompson, K. Control and Ideology in Organisations. Open University Press, Milton Keynes, 1980, 2 16-236.

$3^{8}$ Wadsworth, M. E. J., Sinclair, S. and Wirz, H. M. A Geriatric day hospital and its system of care. Social Science and Medicine 6, (1972), 507-525.

39 Whitehead, T. and Mankikar, G. Geriatric psychiatry in the general hospital. The Lancet, (1 5 June, 1974), I $213-1215$.

40 Op. cit.

41 For a comparison see Wadsworth et al., op. cit.

42 Peach, H. and Pathy, M. S. Social support of patients attending a geriatric day hospital. Journal of Epidemiology and Community Health 32, (1978), $215^{-2} 18$.

43 Rathod, N. H. and Vandrey, B. H. Factors associated with assignment to treatment. Acta Psychiatrica Scandinavica. 47 (4), 1971, 368-398.

44 Bergmann, K., Foster, E. M., Justice, A. W. and Matthews, V., Management of the demented elderly patient in the community. British Joumal of Psychiatry 132, (1978), 441-449.

45 Cosin. L. Architectural and functional planning for a geriatric day hospital. International Journal of Social Psychialry 17, 2 (1971), 133-140. 
46 Unlike Robertson et al. (op. cit.) who deliberately did not interview patients because they expected their views to differ from staff, we do consider patients to be a significant constituent group of the day hospital. However, the collection and analysis of data generated by psychogeriatric patients themselves raises such substantial practical and methodological problems as to be beyond the scope of this paper.

47 For a recent study see Blaxter, M. The Meaning of Disability: A Sociological Study of Impairment. Heinemann, London, 1976.

48 Weiss, Carol H. Evaluation Research. Prentice-Hall, Englewood Cliffs, New Jersey, 1972, pp. 24-25. Amongst the problems she lists are the following. Goals are often hazy and ambiguous. In pursuing goals unexpected accomplishments are often achieved additionally and sometimes instead. Programmes consist of 'congeries of activities, people and structures'. And in its simplest form the evaluative question neglects the issue of why, which is quite as important as the issues of how well.

49 Goldberg, E. M. and Connelly, W. Evaluative Research in Social Care. Heinemann, London, I981, p. $3{ }^{1} 3$.

50 Kelman, H. R. The underdevelopment of evaluative research on health services for the elderly in the United States. International Joumal of Health Services ro, 3 (I 980$), 50$ I-5I I.

5 I Smith, G. Op. cit. p. 204.

52 Hall, P., Land, H., Parker, R. and Webb, A. Change, Choice and Confict in Social Policy. Heinemann, London, 1975, 127.

53 Ibid. pp. 1 27-1 29.

54 Strauss, A., Schatzman, L., Ehrlich, D., Booker, R. and Shabshin, M. The Hospital and Its Negotiated Order. In Salaman, J. and Thompson, K. (eds) People and Organisations. Longmans for the Open University Press, 1973, p. $3^{18 .}$

55 It could be argued that it is a mistake to link pluralistic evaluation methods to the pluralistic model of policy analysis. It may well be thought equally possible to use pluralistic methods within a 'conflict' model of policy analysis, or any other theoretical framework for that matter. Here we note only that in the course of our research we came to adopt pluralistic methods by viewing the Hospital as a pluralistic institution. We propose to discuss the general point at greater length elsewhere, for it involves issues which are beyond the scope of this paper. We are grateful to an anonymous referee for raising the matter.

\section{Acknowledgements}

This paper is based upon one section of a research project conducted within the Department of Social Administration and Social Work, University of Glasgow, and funded by the Scottish Home and Health Department. We are grateful to the Health Board and to the staff concerned for their generous assistance. Andy Alaszewski, David Robinson and two anonymous referees commented most helpfully on an earlier draft. Thanks are also due to our secretaries Mrs Helen Dalrymple in Glasgow and Ms Sue Needham in Hull. 